\title{
Obituary: Prof. Dr. Hans-Joachim Seifert
}

(09. 11. 1930-08. 08. 2017)

๑ Akadémiai Kiadó, Budapest, Hungary 2020

The German Association of Thermal Analysis, GEFTA, is deeply sad to inform the scientific community of thermoanalysts and calorimetrists that our Honorary member, Professor Dr. Hans-Joachim Seifert, passed away August 8, 2017, in his 87th year.

Immediately after the formation of GEFTA in 1974, Hans Seifert got in close connection and cooperation with GEFTA and influenced and supported its activities for several decades. From 1977 to 1980, he was GEFTA's chairman; later, he became its Honorary member.

One year before, in 1973, he became Professor at the Gesamthochschule Kassel, where he undertook his basic scientific work on the thermochemistry of halides and halogenocomplexes making him a widely known specialist in this field of inorganic chemistry. This was one of the reasons to be appointed, in 1982, Vice-President of ICTAC, the International Confederation for Thermal Analysis and Calorimetry. From 1985 to 1988, he was elected President of ICTAC. This was the period of more and more intensified collaboration also with the East-European countries and of a revitalization of the interaction between ICTAC and ESTAC. The "homogenization" of their congress schedules was primarily intended by the scientific convictions of Hans Seifert. In 1994, his work for the international scientific cooperation was acknowledged by ICTAC's Service award.

We gratefully remember Hans Seifert as an very active GEFTA chairman who had remarkable skills as an intensively discussing session's chairman at numerous conferences, as a serious promoter of younger scientists.

GEFTA honoured the scientific achievements of Hans Seifert by awarding him the Netzsch-GEFTA-Award in 1987.

For the GEFTA board Dirk Walter, Steffen Neuenfeld and Michael Feist

Publisher's Note Springer Nature remains neutral with regard to jurisdictional claims in published maps and institutional affiliations. 